\title{
DISLODGED TEETH IN FOUR INTACT CHILD MUMMIES FROM GRAECO/ROMAN EGYPT (332 BCE - C. 395 CE) - CHILD ABUSE, ACCIDENT OR CARELESS EMBALMERS?
}

\author{
Janet Davey ${ }^{1,2}$, Pamela J. G. Craig ${ }^{3}$, Olaf. H. Drummer ${ }^{1,2}$ \\ ${ }^{1}$ Department of Forensic Medicine, Monash University, Melbourne, Australia \\ ${ }^{2}$ Victorian Institute of Forensic Medicine, Southbank, Australia \\ ${ }^{3}$ Unit of Oral Anatomy, Medicine \& Surgery, Melbourne Dental School, \\ The University of Melbourne, Melbourne, Australia
}

\begin{abstract}
In a computerised tomographic (CT) scanning and x-ray imaging of four ancient Egyptian Graeco/Roman child mummies, it was observed that deciduous teeth had been dislodged and that the cervical spines were flexed. The objective of this study was to determine whether the cause of the tooth loss and spinal flexion were linked or whether they related to ante-mortem accident or abuse.

Three mummies were examined using high speed helical CT scanners and the fourth mummy was examined using $\mathrm{x}$-ray film. The images were loaded into an advanced visualisation workstation for further examination and to provide accurate data to identify exfoliated teeth and the flexion of the cervical spine.

The age range of the children was approximately eighteen months to six years. The study showed that in two cases the dislodged teeth were within the oral cavity and in the third case the dislodged teeth were found close to empty sockets. In the fourth mummy two upper teeth were dislodged but could not be identified in the oral cavity due to the lack of clarity in the x-ray films.

In all cases natural exfoliation or dental extraction as a cause of tooth loss was rejected due to the age of each child and identification of dislodged teeth which lacked evidence of root resorption. The reason for the dislodgement of teeth appeared to be due rough post-mortem handling by embalmers when
\end{abstract}


grasping the mandible to flex the cervical spine and manipulate the head towards the chest. Ante-mortem accident, child abuse, periodontal disease or extractions were rejected as the cause of tooth loss.

Keywords: mummies, embalming, ancient Egypt, CT

\section{INTRODUCTION}

In a radiological study of four ancient Egyptian child mummies from the Graeco/Roman Period (332 BCE - c. 395 CE) examples of unusual tooth loss and retention of these teeth within the oral cavity was identified (14). The loss of teeth was investigated to find if it was caused by natural exfoliation, accident due to deliberate injury or related to a particular mummification procedure.

The children had died between the ages of approximately eighteen months and seven years. In Graeco/Roman Egypt the likelihood of death due to disease, injury, fatal attack, misadventure or child abuse was considered possible (11). Living close to water sources in the Nile Valley or in the oases presented the environmental dangers of drowning, attack by animal and parasitic infections $(3,23)$. Children may also have suffered from inflammatory diseases or nutritional deficiencies, which may in turn have caused a reduced life expectancy $(9,21,25)$.

Following the death of a child, where sufficient resources were available, the body was mummified by embalmers who desiccated the body with natron. This was the preferred method implemented by the ancient Egyptians to delay or halt the putrefaction of bodies in preparation for burial $(1,2)$. Natron is a naturally occurring salt found in Egypt which consisted of sodium chloride, sodium sulphate, sodium bi-carbonate and sodium carbonate in varying quantities (10). The desiccation process was often so efficient that it was possible to preserve most parts of the body including the soft tissues of the gums and other structures in the oral cavity. Linen packages impregnated with natron may have been placed within the oral cavity in an effort to inhibit decay of the supporting tissues (16). If the tissues had decomposed, straight rooted teeth may have easily exfoliated post-mortem or accidentally dislodged during embalming if sufficient force was applied to the area (4).

Knowledge of ancient mummification practices was originally based on ancient texts until the advent of investigations of mummified bodies using modern scientific and medical technology $(6,8,12,13,19,22)$. Reports on mummies have shown that the level of care taken by the embalmers may not always have been up to a standard where the body was prepared in an orderly 
manner. Careless handling caused post-mortem damage or allowed for foreign inclusions to remain within the wrappings $(15,26)$.

Recently the manipulation of raw CT scan data in advanced visualisation workstations has provided more specific information about the state of the body and in particular the dentition, the sockets and in one case deliberate dental intervention $(4,27)$. The radiographic appearance of deciduous teeth can determine whether or not they were naturally exfoliated, by observing whether the roots were present or had been gradually resorbed until only the crown remained (20). Deciduous teeth of children are usually naturally exfoliated between the ages of five years and 12 years as they are gradually replaced by the permanent teeth $(7,24)$. Pathological loss of teeth in children, apart from loss through dental decay or extraction is extremely rare, although not unknown $(18,28)$.

The objectives of this research were to identify which teeth were missing from sockets, if they remained in the oral cavity and if the teeth were lost due to natural exfoliation, trauma, dental intervention or forceful rough handling by embalmers when the head was forced into a particular position which may have dislodged the teeth from their alveolar sockets.

\section{MATERIALS AND METHODS}

The child mummies were numbered one to four for identification in this study. Computerised tomography (CT) scans had been conducted at various sites on all mummies except for mummy four which was investigated using $\mathrm{x}$-ray film (Table 1). The CT scans provided raw data in sufficient detail for comprehensive study of the dentition and supporting tissue. In particular the $64 \mathrm{x} 0.5 \mathrm{~mm}$ per second acquisition with the Toshiba Aquilion 64 CT scanner provided excellent images of mummies one and two.

The raw CT scan data was loaded into a Vitrea 2 advanced visualisation workstation (Vital Images, Minnetonka, MN, USA) at the Victorian Institute of Forensic Medicine (VIFM), Melbourne, Australia. Various functions of the workstation constructed virtual sagittal, coronal and multi-planar reconstructions of areas of interest. This enabled the dentition to be examined for periodontal disease, blunt force injuries and dislodged or exfoliated teeth. Where it was not possible to confidently identify the position or identity of an individual tooth, the virtual endoscopy function was engaged which allowed for viewing within the oral cavity and the surrounding areas. An image of each dislodged tooth was examined to confirm whether the root had been resorbed and if it was at a stage of development consistent with the estimated age of the child at death. 
Table 1. Details of the mummy's studies and exfoliated teeth

\begin{tabular}{|c|c|c|c|c|c|c|c|c|}
\hline $\begin{array}{l}\text { Name } \\
\text { (source } \\
\text { and identi- } \\
\text { fication) }\end{array}$ & $\begin{array}{l}\text { Approx. } \\
\text { Age } \\
\text { (years) }\end{array}$ & Sex & $\begin{array}{l}\text { CT } \\
\text { scanned }\end{array}$ & $\begin{array}{l}\text { Teeth } \\
\text { dis- } \\
\text { lodged }\end{array}$ & $\begin{array}{l}\text { Teeth } \\
\text { in } \\
\text { mouth }\end{array}$ & $\begin{array}{l}\text { Tooth } \\
\text { loss- ex- } \\
\text { foliation }\end{array}$ & $\begin{array}{l}\text { Tooth } \\
\text { loss- ex- } \\
\text { traction }\end{array}$ & $\begin{array}{l}\text { Root } \\
\text { Resorp- } \\
\text { tion }\end{array}$ \\
\hline $\begin{array}{l}\text { Mummy } \\
\text { One BM } \\
\text { EA30362 }\end{array}$ & $5-6$ & $F$ & $Y^{1}$ & $Y$ & $Y$ & $\mathrm{~N}$ & $\mathrm{~N}$ & $\mathrm{~N}$ \\
\hline $\begin{array}{l}\text { Mummy } \\
\text { Two BM } \\
\text { EA54053 }\end{array}$ & $1-2$ & $\mathrm{U} / \mathrm{K}$ & $Y^{1}$ & $Y$ & $Y$ & $\mathrm{~N}$ & $\mathrm{~N}$ & $\mathrm{~N}$ \\
\hline $\begin{array}{l}\text { Mummy } \\
\text { Three AMM } \\
\text { 27C NMA }\end{array}$ & $1.5-3$ & $M$ & $Y^{3}$ & $Y$ & $Y$ & $N$ & $\mathrm{~N}$ & $\mathrm{~N}$ \\
\hline $\begin{array}{l}\text { Mummy } \\
\text { Four Sch- } \\
\text { leitheim } \\
\text { Switzerland }\end{array}$ & $2-3$ & $\mathrm{U} / \mathrm{K}$ & $\begin{array}{c}\text { N (Zurich } \\
\text {-X-ray } \\
\text { films) }\end{array}$ & $Y$ & $\mathrm{~N}$ & $\mathrm{~N}$ & $\mathrm{~N}$ & $\mathrm{U} / \mathrm{K}$ \\
\hline
\end{tabular}

Key: BM = British Museum, London UK, NMA = National Museum of Antiquities, Leiden, the Netherlands

$\mathrm{Y}=$ Yes, $\mathrm{N}=\mathrm{No}, \mathrm{M}=$ Male, $\mathrm{F}=$ Female, $\mathrm{U} / \mathrm{K}=$ unknown

${ }^{1}$ Toshiba 64 (Toshiba Medical Systems Corporation, Tochigi, Japan) at Blackheath Hospital/BMI Healthcare, London, UK

${ }^{3}$ Siemens scanner, Leiden, the Netherlands

In the case of mummy four copies of the x-ray films were examined on the Vitrea 2 workstation. The reduced clarity of the reproduction of the original $\mathrm{x}$-ray films presented problems with the identification of individual teeth but the quality of the images was sufficient to proceed with the examination.

Epidemiologically derived dental development data charts are not available for ancient Egyptian children so modern development charts were used as a guide to predict the approximate age of each child at death. Radiographic images of the teeth were compared with the chart for expected dental status at a particular age. Any evidence of dislodgement, extraction or exfoliation was recorded. Where possible the origin of each exfoliated tooth was determined by virtual comparison with an empty socket. 


\section{RESULTS}

In mummy one all four deciduous central incisors, upper and lower were dislodged. Three of the avulsed teeth were lying free on the tongue and retained roots with little indication of any root resorption. There was not any evidence of periodontal disease, extraction or trauma. A radio-opaque object was identified within the oral cavity. Dental developmental age was estimated to be five to six years. The chin had been forced towards the sternum and the upper cervical vertebra was in disarray (Fig. 1).

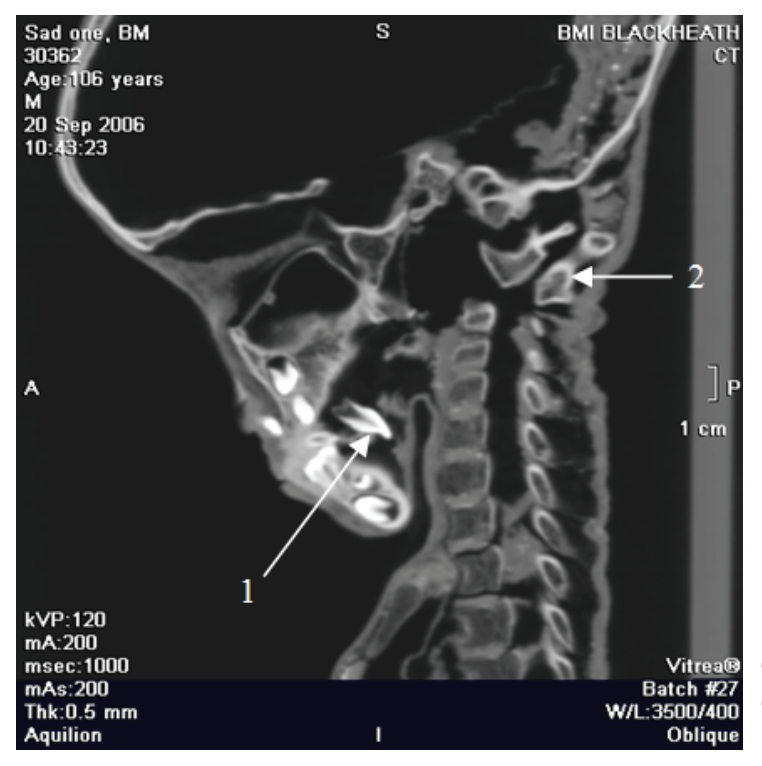

Figure 1. Mummy one. Arrow 1 indicates the position of dislodged incisor tooth towards the back of the tongue. Arrow 2 indicates the disruption of the cervical spine when the head was pushed forward on to the chest.

The dental development of mummy two showed that the child was approximately one to two years of age at the time of death. The deciduous lower canine on the left side of the mandible was avulsed and was found within the oral cavity close to the empty socket. There was no evidence of root resorption, periodontal disease or trauma to the oral cavity. The chin had been forced downwards towards the sternum which had caused flexion of the cervical spine (Fig. 2). 


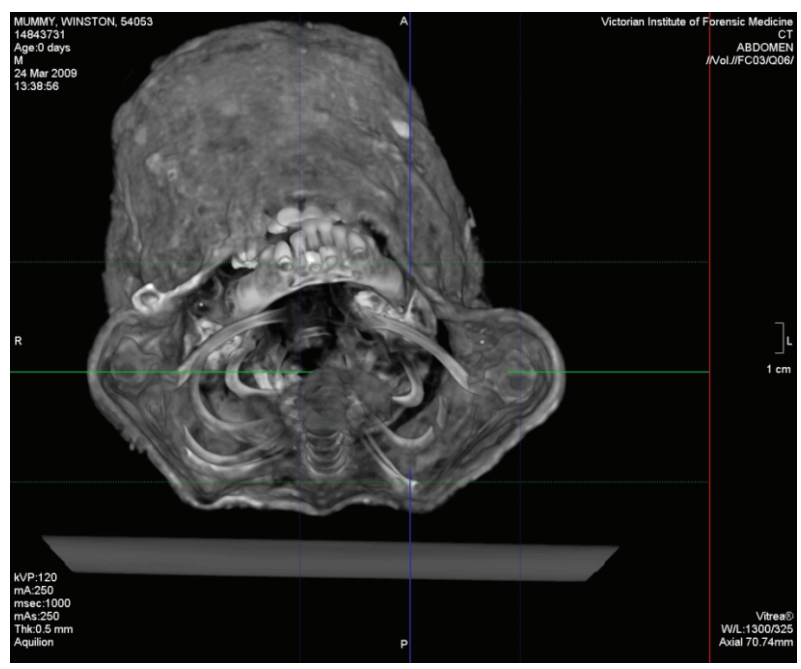

Figure 2. Mummy two. The deciduous lower canine on the left side of the mandible was avulsed and was found within the oral cavity close to the empty socket laterally to the tongue.

On the left side of the mandible of mummy three the second deciduous molar was dislodged but lying within the socket. The contra-lateral deciduous molar was dislodged and appeared to be in the buccal sulcus of the left cheek. No evidence of periodontal disease, injury or intervention was detected. The cervical spine was flexed with the chin angled towards the sternum. The age of the child at death was estimated to be between 18 months and three years (Fig. 3).

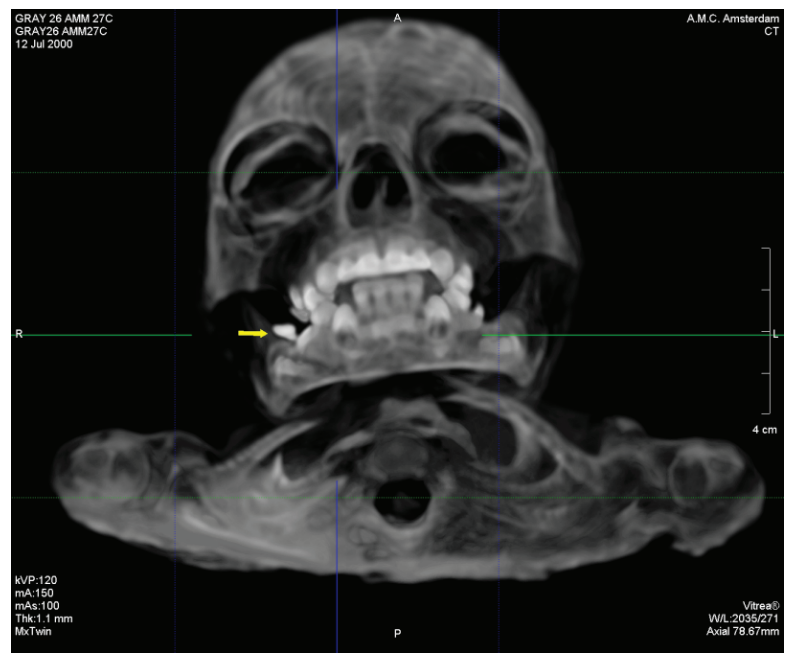

Figure 3. Mummy three. On the left side of the mandible the second deciduous molar was dislodged but lying within the socket and the contra-lateral deciduous molar was dislodged and appeared to be adjacent to the left cheek. 
The $\mathrm{x}$-ray films of mummy four were difficult to read on the advanced visualisation workstation as they were two dimensional radiographic images and the condition of the mummified body was poor. Deciduous and unerupted permanent teeth were visible. It appeared that the deciduous upper left canine and the deciduous first and second molar teeth were missing in the maxilla and were not found. It was not possible to determine if periodontal disease or injury had occurred. The chin had been forced towards the chest and the age at death was estimated at between one and three years (Fig. 4).

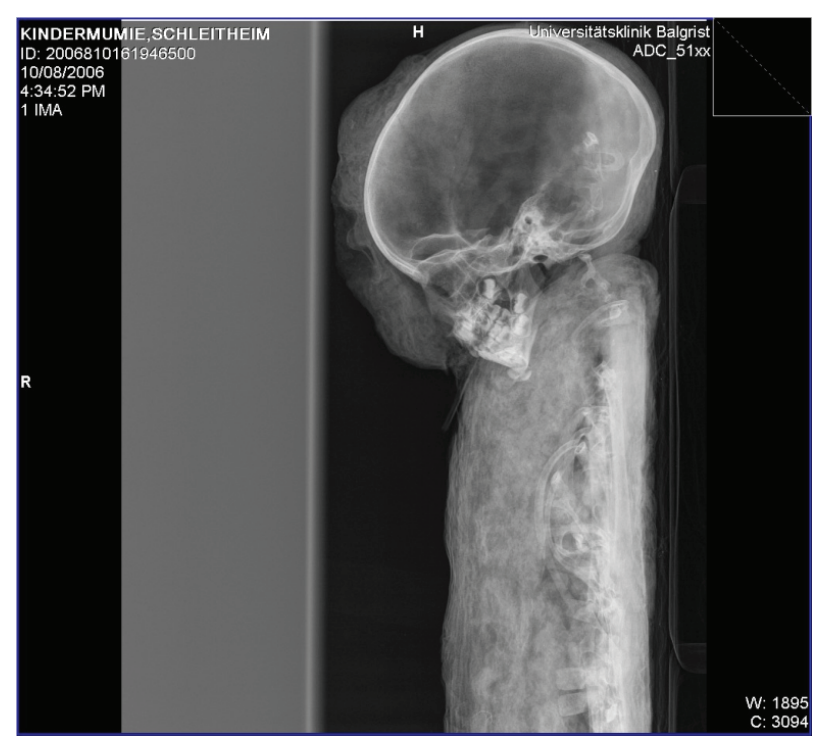

Figure 4. Mummy four. Deciduous and unerupted permanent teeth were visible. It appeared that the deciduous upper left canine and the deciduous first and second molar teeth were missing in the maxilla and were not found.

\section{DISCUSSION}

There was no identifiable damage to the mouths of the mummies that would suggest post-mortem blunt force trauma although this cannot be discounted. Rough handling by the embalmers was probable, particularly if natron had been introduced forcibly into the mouth. The radio-opaque object in the mouth of mummy one cannot be positively identified but may represent a linen package impregnated with natron. Whatever the identity of the opacity the discovery of it in the oral cavity suggested that its introduction may have dislodged teeth (5).

The normal age for the exfoliation of the deciduous incisors is five to 12 years. Except for mummy one, natural exfoliation of the teeth would not be expected as the younger children were less than three years at time of death. In the case of mummy one where the approximate age was estimated at five to six years at death if there had been natural exfoliation it would be expected that 
a single or possibly two incisor teeth would be missing and not found as they would have been lost before death. In this case four central incisor teeth had been avulsed complete with intact roots, which suggested that force was used in the area. One of the dislodged teeth was discovered under the upper lip. This unusual occurrence has been previously reported (5).

The left deciduous mandibular canine found close to its socket in the oral cavity of mummy two is unusual in that more force would have been necessary to dislodge this tooth than would be required for an incisor; as it is a more robust tooth. If rigor mortis had set in and not resolved it may have been difficult to force the mouth open (17). Therefore a solid object would have been necessary to open the mouth.

A general report on the dentition of mummy three had been published without information about specific teeth or their position within the oral cavity. The report had indicated that there was no evidence of dislodgement, exfoliation, dental disease or other pathology (22). This study identified that two teeth were dislodged and one of these teeth was found inside the oral cavity. As with reports on previous mummies it seems that considerable force would need to be applied to dislodge these teeth.

In the case of mummy four it was possible that the upper left deciduous canine and the upper deciduous molar teeth were dislodged during mummification as natural exfoliation would not be expected in such a young child. The flexed cervical spine suggested that the embalmers used force to manipulate the head towards the chest.

In all mummies, where the site of tooth loss was clearly visible there was no evidence of ante-mortem dental intervention in the form of ragged sockets that would be expected if the child had died shortly after extraction of teeth. This observation was supported by the presence of dislodged teeth in the oral cavities of mummies one to three. If teeth had been extracted it would be expected that the teeth were discarded rather than being returned them to the mouth.

In each case the hyper-flexion of the cervical spine and the chin forced towards the sternum suggested that extreme force was used to manipulate the bodies into this unnatural position. If the mandible had been grasped to manoeuvre the head into position it would be possible that teeth were dislodged during this process. The inward force required may explain the position of the dislodged teeth in the mummies. To force the mouth open it would require the insertion of a tool similar to a screwdriver that could be pushed between the teeth and rotated. Following the initial opening further instruments would be needed to increase the opening until there was sufficient room to manoeuvre the head into the required position. Evidence of periodontal disease was not found 
and subsequent tooth loss, caused by inflammatory diseases or nutritional deficiencies appeared to be unlikely but cannot be discounted. No evidence was found of obvious trauma that suggested deliberate injury or abuse.

\section{CONCLUSION}

The most plausible explanation for the dislodgement of teeth was not pathology but was the presumed practice by embalmers of forcing the head towards the chest by gripping the mandible, pulling it forward and dislocating the cervical spine. Teeth with single roots would be more likely to be dislodged but if the force was exerted further back along the body of the mandible, posterior teeth could also have been lost. Extreme decomposition of the soft tissues would result in some of the teeth falling out of the sockets if the body were moved about or if the oral structures suffered interference during mummification.

\section{ACKNOWLEDGEMENTS}

The authors wish to acknowledge Dr John Taylor of the British Museum, Dr Frank Rühli of the University of Zurich, Dr Maarten Raven of the National Museum of Antiquities, Leiden, the Netherlands for their support and in some cases providing the raw CT scan data for this study. In addition the authors wish to thank Craig Hagenmaier and Lauren Fogarty both formerly of Toshiba UK and Toshiba Australia, respectively, for their expert radiological assistance.

\section{REFERENCES}

1. Aufderheide A.C. (2003). The Scientific Study of Mummies. Cambridge University Press. Cambridge.

2. Aufderheide A.C., Zlonis M., Cartmell L.L., Zimmerman M.R., Sheldrick P., Cook M., Molto J.E. (1999). Human Mummification Practices at Ismant elKharab. JEA, 85, 197-210.

3. Bruschi F., Masetti M., Locci M.T., Ciranni R., Fornaciari G. (2006). Cysticercosis in an Egyptian Mummy of the Late Ptolemaic Period. Am J Trop Med Hyg, 74, 598-599.

4. Craig P., Davey J. (2003). A Radiographic Study of the Head of a Child from Graeco/Roman Egypt. Buried History, 39, 21-28.

5. Davey J., Bowyer P., Gize A., Hagenmaier C. et al. (2014). Standard of Mummification in Graeco-Roman Child Mummies. Yrbk Mummy Studies, 2, 81-86. 
6. Dawson W.R., Gray P.H.K. (1968). Catalogue of Egyptian Antiquities in the British Museum: 1, Mummies and Human Remains. British Museum Press. London.

7. Demirjian A., Glodstein H. (1976). New system for dental maturity based on seven and four teeth. Ann Hum Biol, 3, 411-421.

8. Diodorus Siculus (1814). The Historical Library of Diodorus in fifteen books to which are added the fragments of Diodorus. J. Davis. London.

9. Donoghue H.D., Lee O.Y., Minnikin D.E., Besra G.S., Taylor J.H., Spigelman M. (2010). Tuberculosis in Dr Granville's mummy: a molecular re-examination of the earliest known Egyptian mummy to be scientifically examined and given a medical diagnosis. Proc R Soc B, BS, 277, 51-56.

10. Edwards H.G.M., Currie K.J., Ali H.R., Jorge Villar S.E., David A.R., Denton J. (2007). Raman spectroscopy of natron: shedding light on ancient Egyptian mummification. ABC, 388, 683-689.

11. Filer J. (1995). Disease. British Museum Press. London.

12. Harris J.E., Weeks K.R. (1973). X-Raying the Pharaohs. Charles Scribner's Sons. New York.

13. Herodotus (1954). The Histories, Book 2. Penguin. Harmondsworth, 127-128.

14. Ikram S., Dodson A. (1998). The Mummy in Ancient Egypt. Thames \& Hudson. London.

15. Isherwood I. (1979). Radiology of the Manchester Mummies. In: David A.R. (ed.), The Manchester Museum Mummy Project. Manchester University Press. Manchester, 25-77.

16. Jackowski C., Bollinger S., Thali M.J. (2008). Common and Unexpected Findings in Mummies from Ancient Egypt and South America as revealed by CT. RadioGraphics, 28, 1477-1492.

17. Knight B. (2004). Forensic Pathology. 3rd ed. Arnold. London.

18. Leek F.F. (1967). The Practice of Dentistry in Ancient Egypt. JEA, 53, 51-58.

19. Lynnerup N. (2007). Mummies. Yrbk Phys Anthropol, 50, 162-190.

20. Moorees C.F.A., Fanning E. A., Hunt E.E. (1963). Age variation of formation stages for ten permanent teeth. JDE, 42, 1490-1502.

21. Nerlich A., Zink A., Hagedorn H.G., Szeimies U., Weyss C. (2000). Anthropological and palaeopathological analysis of the human remains from three "Tombs of the Nobles" of the necropolis of Thebes-west, upper Egypt. Anthropol Anz, 58, 321-343.

22. Raven M.J.T., Taconis W.K. (2005). Egyptian Mummies: Radiological Atlas of the Collections in the National Museum of Antiquities in Leiden. Brepols, Turnhout, 104-106.

23. Rutherford P. (1999). Immunocytochemistry and the Diagnosis of Schistosomiasis: Ancient and Modern. Parasitology Today, 15, 390-391. 
24. Smith H. (1991). Standards of human tooth formation and dental age assessment. In: Kelley M.A., Larsen C. S. (eds), Advances in Dental Anthropology. Wiley-Liss. New York, 143-168.

25. Stevens E.E., Patrick T.E., Pickler R. (2009). A History of Infant Feeding. J Perinat Educ, 18, 32-39.

26. Taylor J. (2004). Mummy: the inside story. British Museum Press. London.

27. Wade A.D., Garvin G.J., Hurnanen J.H., Williams L.L., Lawson B., Nelson A.J., Tampieri D. (2012). Multidetector CT of Egyptian mummies of the Redpath Museum. RadioGraphics, 32, 1235-1250.

28. Wood R.E, Housego T., Nortje C.J., Padayachee A. (1987). Tuberculous osteomyelitis in the mandible of a child. Pediatr Dent, 9(4), 317-320.

\section{Address for correspondence:}

Dr Janet Davey

Victorian Institute of Forensic Medicine

57-83 Kavanagh Street

Southbank, Australia 3006

E-mail: janetd@vifm.org 